\title{
Recurrent Cholera Outbreaks in Sub-Saharan Africa: Moving beyond Epidemiology to Understand the Environmental Reservoirs and Drivers
}

\author{
Willis Gwenzi ${ }^{1, *(D)}$ and Edmond Sanganyado ${ }^{2}$ (D) \\ 1 Biosystems and Environmental Engineering Research Group, Department of Soil Science and Agricultural \\ Engineering, University of Zimbabwe, P.O. Box MP167, Mt. Pleasant, Harare, Zimbabwe \\ 2 Marine Biology Institute, Shantou University, Shantou 515063, China; esang001@ucr.edu \\ * Correspondence: wgwenzi@yahoo.co.uk or wgwenzi@agric.uz.ac.zw; Tel.: +263-024-303211 (ext. 15548)
}

Received: 30 November 2018; Accepted: 26 December 2018; Published: 7 January 2019

\begin{abstract}
Recurrent cholera outbreaks in sub-Saharan Africa (SSA) attracted a lot of research interest, raising questions about the effectiveness of current prevention and control methods. However, research on cholera and other water-borne diseases in Africa is dominated by epidemiological studies, while investigations on the environmental drivers and reservoirs of cholera remain scarce. The current discourse relating cholera to the environment in SSA is often limited to the rudimentary statement that, "cholera is caused by the consumption of contaminated water and food". Yet, beyond this simplistic view, literature elsewhere shows that cholera outbreaks are controlled by its complex interactions with environmental drivers and reservoirs. This brings to question whether cholera can be eradicated in SSA without understanding these complex interactions. The current review seeks to (1) highlight the nature and dynamics of recent cholera outbreaks in SSA, (2) discuss the importance of environmental reservoirs of Vibrio cholerae, and anthropogenic and hydroclimatic drivers in controlling the dynamics of cholera outbreaks, and (3) highlight key knowledge gaps and future research directions, and the need to harness emerging research tools such as modeling, machine learning, data mining, and genomics techniques to better understand the cholera dynamics. By bringing to fore these often-overlooked issues in cholera research, we seek to stimulate discussion, and promote a shift toward cross-disciplinary research on cholera and other water-borne diseases in SSA and beyond.
\end{abstract}

Keywords: cholera outbreaks; cholera epidemiology; environmental reservoirs; contaminated drinking water

\section{Introduction}

Sub-Saharan Africa (SSA) experienced recurrent cholera outbreaks, contributing to $86 \%$ and $99 \%$ of reported cases and deaths worldwide in 2011 [1]. In 2017 and 2018, cholera outbreaks were reported in seven SSA countries: Cameroon, Democratic Republic of Congo, Tanzania, Kenya, Mozambique, and Zambia, with the most recent reported in Zimbabwe [2]. In fact, Zimbabwe experiences frequent cholera outbreaks with the most devastating one in 2008, which had a total of 11,735 cases, 484 deaths with a high case fatality ratio (CFR) of $4 \%$, reaching as high as $20-30 \%$ in remote areas [3,4]. The most recent outbreak had 3621 cases, 32 deaths, and $98 \%$ of the cases were reported in densely populated Harare [5]. Contrary to the decreasing global trend in CFR of cholera, the ratio remains nearly constant at $2 \%$ [1]. This potentially points to the ineffectiveness of current prevention and control methods in Africa.

Research on cholera and other water-borne diseases in Africa is largely limited to the medical discipline, i.e., the predominance of epidemiological studies. Specifically, the bulk of research on 
cholera is largely limited to the following: (i) disease incidences and distribution [6,7], and (ii) identification and diversity of Vibrio cholerae strains [8] and antimicrobial resistance [9-11]. In contrast, little information exists on the ecology of cholera in Africa, particularly the environmental drivers and reservoirs. In most studies and media reports on cholera, reference to the environment is often limited to the general statement that, "cholera is caused by the consumption of contaminated water and food" [5]. Limited follow-up studies are conducted after the outbreak to establish the exact source of contamination. Moreover, little information exists on the effectiveness of the various shortand long-term interventions in the control of cholera [12]. Furthermore, the hotspot reservoirs of $V$. cholerae, the bacterium causing cholera, particularly during the inter-epidemic periods are still poorly understood [13-15]. Yet, such information is key for the development of effective methods for the prevention and control of cholera.

Therefore, the current paper posits that understanding the environmental drivers and reservoirs of cholera, and the effectiveness of the prevention and control methods are critical for the eradication of cholera in SSA. This calls for a move beyond just epidemiology, to more cross-disciplinary research that includes comprehensive hydrology, environmental sciences, and climatic science studies, which are often overlooked in cholera investigations $[16,17]$. The current study draws largely from the recent cholera outbreaks in Zimbabwe to address three specific objectives: (1) to highlight the nature and dynamics of recent cholera outbreaks in SSA, (2) to discuss the importance of environmental drivers and reservoirs in controlling the dynamics of cholera outbreaks, and (3) to highlight future research directions and the need to harness emerging research tools to better understand the cholera dynamics. By highlighting these often-overlooked issues in cholera research, the paper seeks to stimulate discussion, and promote a shift toward cross-disciplinary research on cholera and other water-borne diseases in SSA and beyond.

\section{Beyond Epidemiology: Integrating Environmental Sciences into Cholera Research}

\subsection{Rationale for Understanding Environmental Drivers and Reservoirs}

$V$. cholerae, the bacteria that causes cholera, occurs and persists in various aquatic systems such as lakes and rivers [18]. During an outbreak, $V$. cholerae is discharged directly into the environment through human excretions and municipal wastewater effluent [19]. Aquatic systems act as a sink of the $V$. cholerae, and a source considering cholera is a waterborne disease [15]. Once in the aquatic systems, $V$. cholerae may persist and proliferate, and then enter the human body through consumption of contaminated water and food [17]. In this regard, drinking water is the ecotone between aquatic systems and the human body [20]. This cholera loop demonstrates the intricate linkages between the human and environmental components, which play a critical role in sustaining and promoting the persistence of cholera. The behavior of physicochemical and biological components of environmental reservoirs respond to anthropogenic and hydroclimatic forcings, including short- and long-range weather and climatic phenomena such as El Niño-Southern Oscillation, La Niña, and El Niño [21,22]. Moreover, studies on other water-borne diseases demonstrated that their dynamics are driven by climate change and variability, and climatic teleconnections [23,24]. Climatic teleconnections refer to linkages between weather changes or significant positive or negative correlations in the fluctuations of a weather or climatic variable at widely separated points [25]. These climatic teleconnections are linked to outbreaks of human and animal diseases [26]. Climatic signals may propagate from source to distant points through the atmosphere, resulting in disease outbreaks elsewhere [26].

Considering the role played by aquatic systems, hydrology, and atmospheric and climatic systems in cholera dynamics, environmental sciences research should be in the forefront if the goal to end cholera by 2030 is to be met [2]. Using SCOPUS, between 1968 and 2018, there were 950 publications on cholera by researchers from Africa (the search string was TITLE-ABS-KEY (cholera) AND PUBYEAR >1967 AND (LIMIT-TO (AFFILCOUNTRY, "South Africa”) OR LIMIT-TO (AFFILCOUNTRY, “[ $x]^{\prime}$ ), where $[x]$ represents the other individually selected African nations) (Figure 1). Fewer than $10 \%$ of the 
publications were in the environmental science domain, compared to $68 \%$ in medicine. Interestingly, the recommendations by the World Health Organization (WHO) on ending cholera overlooked the role of environmental determinants in cholera outbreaks and the need for multidisciplinary follow-up studies during post-outbreak periods in order to improve the effectiveness of the proposed "multisectoral interventions in cholera hotspots" [2]. The process of explicitly tracking $V$. cholerae sources, dissemination and transmission routes along the reservoir-food/water-human continuum/pathway, which we loosely term "epidemiological forensics" should be a critical component of cholera research. On the other hand, environmental and earth scientists also overlook environmental aspects related to the medical field in their routine research, and often lack analytical equipment for such studies [27]. It is, therefore, understandable and sometimes expected that, when a subject falls between two disparate disciplines, it tends to be neglected by researchers from both disciplines, justifying the need to transcend disciplinary boundaries and even collaborate across disparate disciplines. In view of this, we argue that any research aimed at a complete understanding of the cholera ecology should move beyond epidemiology to include environmental disciplines such as hydrology, atmospheric climatic sciences, and soil sciences.

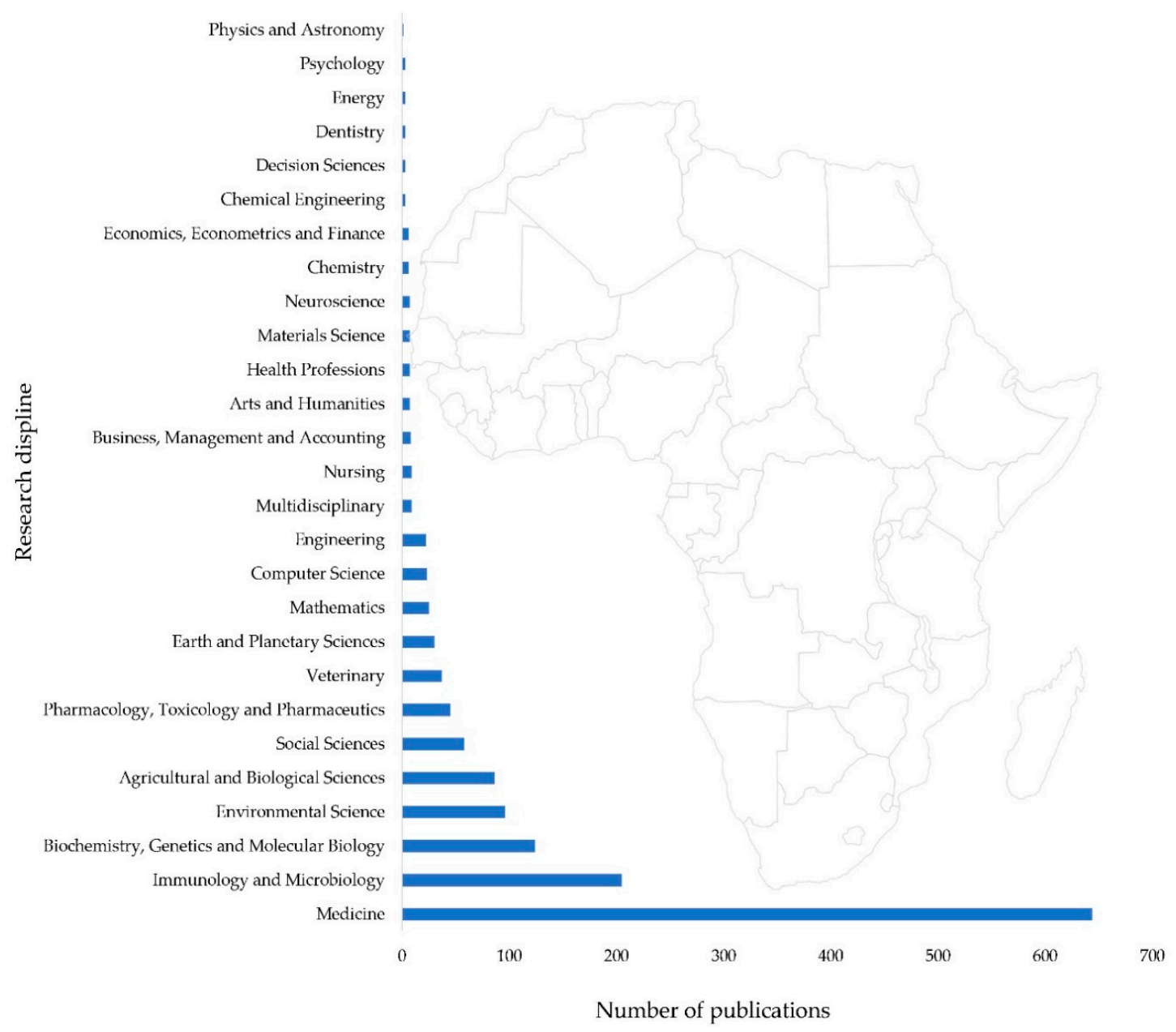

Figure 1. Publications listed on SCOPUS on cholera by researchers from Africa.

\subsection{Environmental Reservoirs: Where Cholera Lurks during Inter-Epidemic Periods}

Environmental reservoirs of cholera refer to where the $V$. cholerae inhabits, grows, and proliferates with the potential to be released and to cause human disease outbreaks $[18,28]$. In this regard, understanding the cholera reservoirs is a critical component of cholera ecology (Figure 2). Studies conducted elsewhere (e.g., Asia and South America) show that brackish, riverine, estuarine, and coastal 
waters, and other physicochemical properties such as salinity promote the persistence and proliferation of $V$. cholerae [18]. Other studies reported complex networks of interactions between $V$. cholerae and sea dwellers and aquatic organisms such as bivalves and shellfish [29]. One study focusing on freshwater systems in several sites in India and Africa (Zanzibar and Malawi) showed that egg masses of chironomids, which are "non-biting midges" (Diptera Chironomidae), were infected by $V$. cholerae in both countries. It is possible that several other aquatic organisms may harbor $V$. cholerae too [30]. In SSA, cholera outbreaks were reported in both coastal (e.g., Kenya, Mozambique, and Tanzania) and non-coastal countries (e.g., Zambia and Zimbabwe), indicating that even non-estuarine aquatic environments could act as $V$. cholerae reservoirs $[15,17]$. Although studies on the dominant environmental reservoirs of $V$. cholerae in SSA are still limited, the recurrent cholera outbreaks point to the existence of hotspot cholera reservoirs [13,31]. Lacking such data, several potential reservoirs could harbor cholera in SSA, including on-site sanitation systems, wetlands, landfills, heavily polluted surface aquatic systems, and groundwater systems.

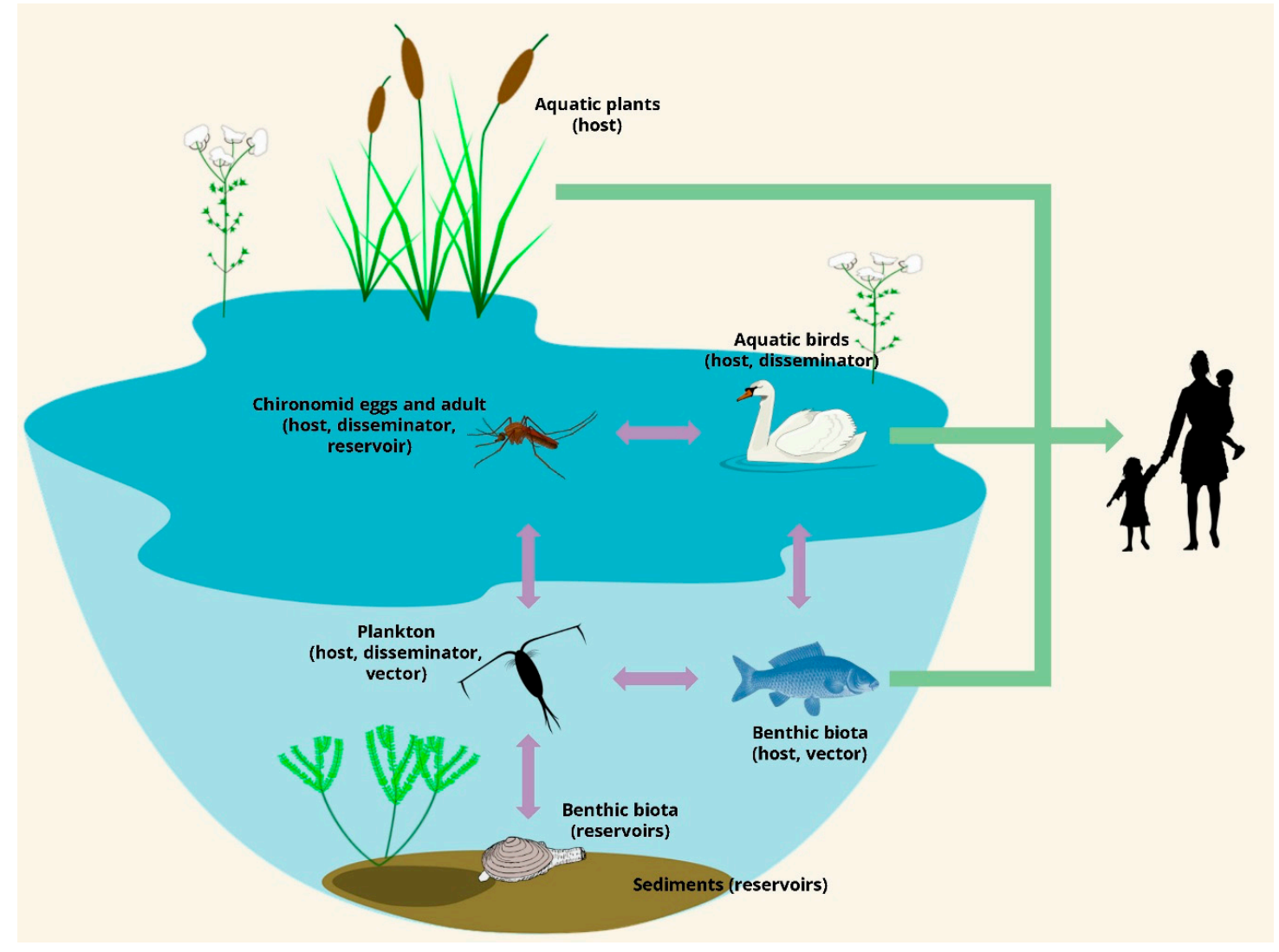

Figure 2. Possible environmental reservoirs, hosts, and vectors of Vibrio cholerae in the aquatic ecosystem (adapted from [28]).

On-site sanitation systems such as septic tanks and pit latrines, which are expected to have saline/brackish water and high nutrient contents, may support the growth and proliferation of cholera. Such sanitation systems are prevalent in most areas without access to centralized wastewater treatment and reticulation systems [32]. In most residential areas and informal settlements, such on-site sanitations systems are in close proximity to drinking water sources such as shallow wells and boreholes [33]. The situation is worse on sandy soils, which have high hydraulic conductivity and limited retention of contaminants [33]. In such cases, there is very high hydrological connectivity between on-site sanitation systems and groundwater sources, and residents are literally "flushing" into drinking water sources. It is interesting to note that the two cholera outbreaks that occurred in Zimbabwe in 2008 and 2018 occurred at the peak of the dry season in September [4,5]. During 
this period, residents are likely to depend mainly on groundwater for potable water supply due to increased demand and unreliable water supplies. Excessive groundwater abstraction during the dry season may lower groundwater levels in shallow wells and boreholes relative to that of on-site sanitation systems, thus increasing the risk of groundwater contamination.

Wastewaters were reported to be a reservoir of various pathogenic organisms and antibiotic resistant bacteria [33,34]. In most SSA countries, wastewater treatment plants are often overloaded and poorly maintained, resulting in discharge of raw or partially treated wastewater into aquatic systems, including wetlands $[33,35]$. Wetlands, which are common in SSA, occur in low-lying areas relative to pollution sources; hence, they receive wastewaters and urban runoff. Together with the predominantly moist conditions, this provides an ideal environment for the survival and proliferation of $V$. cholerae. Moreover, wetlands are hydrologically connected to both surface and groundwater systems via runoff and baseflow, respectively. Like wetlands, surface aquatic systems in SSA are also highly polluted, with several lakes and reservoirs being classified as eutrophic or hypertrophic [32]. Such highly polluted aquatic systems could act as reservoirs and contribute to the recurrent cholera outbreaks. Once in aquatic systems, $V$. cholerae may form a complex network of interactions with other aquatic organisms, including aquatic foods such as fish [29]. Therefore, $V$. cholerae may enter the human body via contaminated water and/or food [28]. Given that aquatic foods such as fish are a key component of human diet, the consumption of such contaminated food may play a critical role in transferring cholera from aquatic systems into humans. To better understand cholera ecology in SSA, there is an urgent need to determine the nature and concentrations of $V$. cholerae in water, and to determine the dominant sources and transfer routes into the human body. Such information is critical for targeting cholera prevention and control methods.

\subsection{What Drives Cholera Outbreaks in SSA?}

The environmental reservoirs, particularly aquatic systems and their biotic components and physicochemical properties, respond to hydroclimatic and anthropogenic forcings [18,28]. Specifically, anthropogenic factors such as poor sanitation and hygiene, human migration, and cross-border movements may also promote the dissemination of cholera [36]. For example, a previous study found cross-border cholera outbreaks contributed to the high cholera burden in SSA, and under-fives and school-going children were the major victims [37].

Weather and climatic divers were also reported to influence the dynamics of cholera outbreaks and other water-borne diseases [38]. For example, studies showed that hydroclimatic factors explain the unique dual peaks observed in cholera outbreaks in the Bengal Delta region in India [39]. The dual outbreak pattern exhibits two peaks in each year, the first one occurring in the spring (March-May), and a second and larger one in the autumn (September-December). In the same study, the authors concluded that the spring outbreak was associated with low river discharges, while the larger autumn outbreak coincided with peak flood volumes that result in large flooded areas during the monsoon. Other studies largely drawn from Asia (e.g., Bangladesh) linked cholera outbreaks to hydroclimatic drivers, including precipitation [38], peak river discharges and floods [40], ambient and sea surface temperature and sea surface height [41], coastal salinity [42], and fecal contamination [43]. The relationship between cholera outbreaks and hydroclimatic drivers, including the dual peak behavior, was also documented in studies based on spatially explicit models [44]. The bulk of these studies were conducted in countries with coastal areas, particularly those in Asia. Accordingly, there is comparatively more literature linking cholera outbreaks to drivers in coastal countries in Asia than Africa.

Unlike most Asian countries which experience monsoonal rains, the bulk of SSA experiences a tropical environment, characterized by wet warm summers (October-March) and cool dry winters (April-September). Moreover, barring a few countries such as Mozambique and Tanzania, SSA consists mainly of inland countries, which lack estuarine and coastal areas. Given this biophysical setting, one would expect different patterns of cholera outbreaks, and their relationships with hydroclimatic 
and anthropogenic variables. Indeed, contrary to the dual peak pattern observed in India, cholera outbreaks in SSA are often characterized by a single annual peak, often coinciding with the wet summer season [45]. For example, peak cholera outbreaks in South Africa occur in January and February during the wet season reflecting its relationship with rainfall peaks and relatively high temperatures [39]. In Zimbabwe, the last two cholera outbreaks, one in 2008 and the recent one in 2018, both occurred at the peak of the dry season in September. Although the reasons for this consistent trend is unclear, it probably reflects over-dependence on contaminated groundwater from potable supplies water during this period, which is necessitated by increasing water demand and the accompanying water shortages. Although quantitative data are still missing, this trend could also reflect the relationship between cholera and hydroclimatic variables such as high temperatures, increased salinity, and concentrations of contaminants in aquatic systems due to limited dilution. Regardless of the drivers, the consistent timing of the outbreaks points to potential cholera linkages to some anthropogenic and hydroclimatic variables, which are yet to be investigated in SSA.

In addition to local and short-range hydroclimatic drivers, studies also demonstrated that climatic teleconnections may drive outbreaks of water-borne diseases, including cholera $[24,26]$. Teleconnections imply that such correlations suggest that information is propagating between the distant points through the atmosphere. Climate teleconnections are linked to outbreaks of human and animal diseases [26]. These results point to the fact that such relationships between cholera and hydroclimatic factors can be further developed into predictive modeling tools to forecast outbreaks of cholera and potentially other water-borne diseases. Such forecasting tools may provide key information to better target financial and public health resources in the control and prevention of cholera in SSA and other regions.

Some studies showed that people infected with human immunodeficiency virus/acquired immune deficiency syndrome (HIV / AIDS), malaria, and tuberculosis often have weakened immunity, and are more susceptible to co-infections with other infectious diseases [46]. Therefore, cholera outbreaks in SSA could be linked to other epidemics such as malaria, tuberculosis, and HIV/ AIDS. However, further research is needed to investigate whether co-infections promote cholera outbreaks.

\section{Harnessing Emerging Research Tools and Charting Future Directions}

\subsection{Emerging Research Tools to Better Understand Cholera Dynamics}

Recent years witnessed various advances in research tools, including analytical methods in microbiological and genomic analyses, remote sensing, data analytics, and process modeling. For example, genomic analysis and other analytical techniques can be used to determine or trace the source of microbial contamination of water and food to environmental reservoirs [47]. Moreover, recent analytical methods based on genomics can be used to relate pathogen strains in humans to those in environmental resources, in the process enabling the identification of the source of contamination [48]. Indeed, the potential of these techniques to improve our understanding of cholera outbreaks was highlighted in earlier reviews [49], and they were applied in some studies in developed countries [50,51]. However, the application of genomic analytical techniques in cholera research remains limited, largely due to the lack of such analytical equipment and expertise. Therefore, advancing cholera research in Africa will require significant investment in such research equipment and capacity building, possibly through North-South cooperation. Furthermore, there is need for a maintenance of $V$. cholerae banks that could be used for physiological analysis (e.g., characterization of chitin receptors associated to $V$. cholerae adherence to aquatic organisms) [52].

Remote sensing and geographic information system (GIS) tools are critical in indirect identification and mapping of environmental reservoirs and drivers such as hydroclimatic variables. In this regard, recent advances in the field, particularly the development of unmanned air vehicle systems (UAVS), which can be used as carriers for multiple sensors, provide critical and potentially low-cost tools for the acquisition of data on environmental variables. In Bangladesh, satellite data were used to 
evaluate the occurrence and spread of cholera in coastal areas from 1992-1995 [41]. A significant correlation between sea surface temperature annual cycles and sea surface height and cholera case reports was observed [41]. In Zimbabwe, spatial estimation of rainfall patterns and air temperature using satellite data helped identify locations were cholera outbreaks began [53]. These results suggest cholera outbreaks could be linked to hydroclimatic conditions. However, in most SSA countries and other developing countries, reliable and long-term hydroclimatic data are often unavailable due to lack of hydrometric stations [54]. The acquisition of remote sensing data may provide a starting point to research into the relationship between $V$. cholerae and environmental variables in SSA. In fact, the lack of long-term hydroclimatic data corresponding to historical data on cholera outbreaks could explain the lack of studies in SSA investigating the relationships between the two.

The field of computer science also witnessed unprecedented development of data analytic tools. Typical examples of such recent advances include the fields of artificial intelligence, machine learning, and data mining [55]. Although not yet fully harnessed in the medical fields, these tools may potentially provide some breakthrough in the field. Recent applications of machine learning in cholera include prediction of susceptibility to cholera using human gut microbiome structure and composition [56], identification of the specific genomic variations that govern the spatial, temporal, and habitat variations in persistence of cholera mobile functions (such as plasmids and phages) [57], and correlations between streamflow and cholera outbreaks [58]. Data mining techniques can also be used to analyze large historical datasets to detect trends and patterns that may not be evident using conventional statistical methods [59]. A previous study mined data from social media and news outlets to estimate the dynamics of the 2010 cholera outbreak in Haiti [60]. In Mali, data mining was used to process satellite data for the identification of risk areas of cholera [61]. The application of these emerging research tools will provide additional insights into cholera dynamics, beyond those provided by the current conventional research methods.

\subsection{Knowledge Gaps and Future Research Directions}

The foregoing discussion demonstrated that cholera research needs to move beyond traditional epidemiological studies, to include other relevant disciplines and research tools. Once the research community acknowledges this, it will be evident that several knowledge gaps pertaining to cholera ecology exist. Here, 11 research questions are raised for future research directions under two thematic areas: (1) environmental reservoirs and drivers, and (2) development of predictive tools (Table 1).

Table 1. Key research questions for future research. HIV/AIDS—human immunodeficiency virus/acquired immune deficiency syndrome; SSA—sub-Saharan Africa.

\begin{tabular}{ll}
\hline \multicolumn{1}{c}{ Environmental Reservoirs and Drivers } & \multicolumn{1}{c}{ Development of Cholera Prediction Tools } \\
\hline $\begin{array}{l}\text { 1. What are the key environmental reservoirs of cholera during the } \\
\text { inter-epidemic periods? }\end{array}$ & $\begin{array}{l}\text { 1. Using predictive tools, what are the hotspot areas } \\
\text { and hot moments in terms of cholera outbreaks? }\end{array}$ \\
\hline $\begin{array}{l}\text { 2. What anthropogenic and environmental variables drives the population } \\
\text { dynamics of Vibrio cholerae and its predators (i.e., vibriophages)? }\end{array}$ & $\begin{array}{l}\text { 2. What anthropogenic and hydroclimatic variables } \\
\text { are best predictors of cholera outbreaks? }\end{array}$ \\
\hline $\begin{array}{l}\text { 3. For each epidemic, what were the specific transfer mechanisms of cholera } \\
\text { from reservoirs into the human body? }\end{array}$ & $\begin{array}{l}\text { 3. How can existing spatial explicit and other } \\
\text { models based on systems analysis tools be further } \\
\text { developed into predictive tools }\end{array}$ \\
\hline $\begin{array}{l}\text { 4. What precursor anthropogenic and hydroclimatic events triggered a } \\
\text { cholera outbreak? }\end{array}$ & $\begin{array}{l}\text { 4. What environmental variables should be } \\
\text { monitored during cholera surveillance to support } \\
\text { the development of predictive models? }\end{array}$ \\
\hline $\begin{array}{l}\text { 5. In addition to local anthropogenic and hydroclimatic drivers, what is the } \\
\text { role of climatic teleconnections in cholera outbreaks? }\end{array}$ & \\
\hline $\begin{array}{l}\text { 6. How are cholera outbreaks linked to other epidemics such as malaria, } \\
\text { tuberculosis, and HIV / AIDS in SSA? }\end{array}$ & \\
\hline $\begin{array}{l}\text { 7. What dominant factors explain the high CFR ratios of cholera in Africa, } \\
\text { and can this be attributed to the development of antibiotic resistance? }\end{array}$ & \\
\hline
\end{tabular}


Indeed, answering these research questions requires more than epidemiologists or medical experts, and should include process modelers, mathematicians, hydrologists, and atmospheric scientists and climatologists, among other experts. This further buttresses our main concept that cholera research in SSA and other regions should move beyond epidemiology and include other allied disciplines. Moreover, emerging research tools such as remote sensing and GIS, genomics, and advanced data analytics will be critical in complementing current conventional methods to address these questions. Notably, most of these research questions are not unique to cholera; rather, they are generic and, hence, may apply to other water-borne diseases prevalent in SSA and other regions.

The current knowledge gaps on understanding the role of environmental reservoirs and drivers in proliferation and transmission of $V$. cholerae are probably caused by the lack of connection between epidemiological and environmental science studies. In Europe, the European Environment and Epidemiology (E3) Network was established to bridge the gap between epidemiological and environmental data, thus providing a link between environmental drivers and infectious diseases [62]. There is need for establishing a similar network of researchers and organizations in Africa that aims at promoting collaboration and sharing of epidemic monitoring, environmental monitoring and characterization, and demographics and socio-economic data. For example, such a network could collate data on socio-economic and environmental factors that drive susceptibility to cholera in communities impacted by other infectious diseases such as tuberculosis, malaria, and HIV / AIDS. However, success in such a network could be hindered by a lack of research resources in low-income countries impacted by cholera. Hence, the African-European Partnership for Neglected Infectious Diseases recommended collaboration between African and European researchers, as well as governmental support in endemic countries [46].

\section{Conclusions}

This current concept paper calls for cholera research to move beyond the current approach which has an epidemiological bias, to include other relevant allied disciplines to better understand the ecology of cholera. Specifically, the concept highlighted the following: (1) the nature and dynamics of cholera outbreaks in SSA, characterized by a single annual peak coinciding with the rainy season; (2) the role of environmental reservoirs and anthropogenic and hydroclimatic drivers in promoting the persistence and dissemination of cholera; (3) future research directions, including 11 specific research questions meant to advance our knowledge on the dynamics of cholera outbreaks in SSA; and (4) the potential opportunities offered by recent advances in research tools such as machine learning, data mining, and remote sensing to cholera research. In summary, the integration of environmental sciences into cholera research could contribute toward better prediction and development of early warning tools for cholera in SSA and elsewhere. Specifically, we believe that the application of emerging tools to systematically analyze historical data on outbreaks could provide clues on cholera hotspots and hot moments, which will, in turn, lead to better targeting of interventions and scarce resources in cholera prevention and control. By drawing attention to these issues, we hope this concept will stimulate discussion, and promote a shift toward cross-disciplinary research on cholera and other water-borne diseases in SSA and beyond.

Author Contributions: Conceptualization, W.G. and E.S.; methodology, W.G.; formal analysis, E.S.; investigation, W.G.; writing —original draft preparation, W.G.; writing-review and editing, E.S. and W.G.; visualization, E.S.

Funding: This research received no external funding.

Conflicts of Interest: The authors declare no conflicts of interest. 


\section{References}

1. Mengel, M.A.; Delrieu, I.; Heyerdahl, L.; Gessner, B.D. Cholera Outbreaks in Africa. In Cholera Outbreaks; Nair, G.B., Takeda, Y., Eds.; Springer: Berlin/Heidelberg, Germany, 2014; Volume 5, pp. 117-144 . ISBN 0070-217X (Print)r0070-217X (Linking).

2. Global Task Force on Cholera Control. Ending Cholera: A Global Roadmap to 2030; World Health Organization: Geneva, Switzerland, 2017.

3. Cuneo, C.N.; Sollom, R.; Beyrer, C. The Cholera Epidemic in Zimbabwe, 2008-2009: A Review and Critique of the Evidence. Health Hum. Rights 2017, 19, 249-264. [PubMed]

4. Mukandavire, Z.; Liao, S.; Wang, J.; Gaff, H.; Smith, D.L.; Morris, J.G. Estimating the reproductive numbers for the 2008-2009 cholera outbreaks in Zimbabwe. Proc. Natl. Acad. Sci. USA 2011, 108, 8767-8772. [CrossRef] [PubMed]

5. World Health Organization Emergencies Preparedness, Response: Cholera-Zimbabwe. Available online: http:/ / www.who.int/csr/don/11-december-2017-cholera-kenya/en/ (accessed on 30 November 2018).

6. Gaffga, N.H.; Tauxe, R.V.; Mintz, E.D. Cholera: A new homeland in Africa? Am. J. Trop. Med. Hyg. 2007, 77, 705-713. [CrossRef] [PubMed]

7. Mintz, E.D.; Tauxe, R.V. Cholera in Africa: A closer look and a time for action. J. Infect. Dis. 2013, $208,4-7$. [CrossRef] [PubMed]

8. Valia, R.; Taviani, E.; Spagnoletti, M.; Ceccarelli, D.; Cappuccinelli, P.; Colombo, M.M. Vibrio cholerae O1 epidemic variants in Angola: A retrospective study between 1992 and 2006. Front. Microbiol. 2013, 4, 1-6. [CrossRef] [PubMed]

9. Kacou-N'douba, A.; Anné, J.C.B.; Okpo, L.S.; Elogne-Kouamé, C.; Koffi, S.; Koffi, V.; N’Guessan, K.; Coulibaly, D.; Dagnan, S.N.; Eholié, S.P.; et al. Antimicrobial resistance of Vibrio cholerae O1 isolated during a cholera epidemic in 2011 in dry season in Cote d'ivoire. J. Infect. Dev. Ctries. 2012, 6, 595-597. [CrossRef] [PubMed]

10. Dalsgaard, A. Vibrio cholerae O1 outbreak isolates in Mozambique and South Africa in 1998 are multipledrug resistant, contain the SXT element and the aadA2 gene located on class 1 integrons. J. Antimicrob. Chemother. 2001, 48, 827-838. [CrossRef]

11. Marin, M.A.; Thompson, C.C.; Freitas, F.S.; Fonseca, E.L.; Aboderin, A.O.; Zailani, S.B.; Quartey, N.K.E.; Okeke, I.N.; Vicente, A.C.P. Cholera Outbreaks in Nigeria Are Associated with Multidrug Resistant Atypical El Tor and Non-O1/Non-O139 Vibrio cholerae. PLoS Negl. Trop. Dis. 2013, 7. [CrossRef]

12. Lessler, J.; Moore, S.M.; Luquero, F.J.; McKay, H.S.; Grais, R.; Henkens, M.; Mengel, M.; Dunoyer, J.; M'bangombe, M.; Lee, E.C.; et al. Mapping the burden of cholera in sub-Saharan Africa and implications for control: an analysis of data across geographical scales. Lancet 2018, 6736, 1-8. [CrossRef]

13. Osei, F.B.; Duker, A.A. Spatial dependency of V. cholera prevalence on open space refuse dumps in Kumasi, Ghana: A spatial statistical modelling. Int. J. Health Geogr. 2008, 7, 1-17. [CrossRef]

14. Akoachere, J.F.T.K.; Masalla, T.N.; Njom, H.A. Multi-drug resistant toxigenic Vibrio cholerae O1 is persistent in water sources in New Bell-Douala, Cameroon. BMC Infect. Dis. 2013, 13. [CrossRef] [PubMed]

15. Rebaudet, S.; Sudre, B.; Faucher, B.; Piarroux, R. Environmental Determinants of Cholera Outbreaks in Inland Africa: A Systematic Review of Main Transmission Foci and Propagation Routes. J. Infect. Dis. 2013, 208, S46-S54. [CrossRef] [PubMed]

16. Constantin de Magny, G.; Thiaw, W.; Kumar, V.; Manga, N.M.; Diop, B.M.; Gueye, L.; Kamara, M.; Roche, B.; Murtugudde, R.; Colwell, R.R. Cholera Outbreak in Senegal in 2005: Was Climate a Factor? PLoS ONE 2012, 7, 1-9. [CrossRef] [PubMed]

17. Rebaudet, S.; Sudre, B.; Faucher, B.; Piarroux, R. Cholera in Coastal Africa: A Systematic Review of Its Heterogeneous Environmental Determinants. J. Infect. Dis. 2013, 208, S98-S106. [CrossRef]

18. Almagro-moreno, S.; Taylor, R.K. Cholera: Environmental Reservoirs and Impact on Disease Transmission. Microbiol. Spectr. 2013, 1, 1-12.

19. Sozzi, E.; Fabre, K.; Fesselet, J.F.; Ebdon, J.E.; Taylor, H. Minimizing the risk of disease transmission in emergency settings: Novel in situ physico-chemical disinfection of pathogen-laden hospital Wastewaters. PLoS Negl. Trop. Dis. 2015, 9, e0003776. [CrossRef] [PubMed] 
20. Ntema, V.M.; Potgieter, N.; Barnard, T.G. Detection of Vibrio cholerae and Vibrio parahaemolyticus by molecular and culture based methods from source water to household container-stored water at the point-of-use in South African rural communities. Water Sci. Technol. 2010, 61, 3091-3101. [CrossRef] [PubMed]

21. Cazelles, B.; Chavez, M.; De Magny, G.C.; Guégan, J.F.; Hales, S. Time-dependent spectral analysis of epidemiological time-series with wavelets. J. R. Soc. Interface 2007, 4, 625-636. [CrossRef]

22. Cazelles, B.; Chavez, M.; McMichael, A.J.; Hales, S. Nonstationary influence of El Niño on the synchronous dengue epidemics in Thailand. PLoS Med. 2005, 2, 0313-0318. [CrossRef]

23. Zell, R.; Krumbholz, A.; Wutzler, P. Impact of global warming on viral diseases: what is the evidence? Curr. Opin. Biotechnol. 2008, 19, 652-660. [CrossRef]

24. Zell, R. Global climate change and the emergence/re-emergence of infectious diseases. Int. J. Med. Microbiol. Suppl. 2004, 293, 16-26. [CrossRef]

25. Liu, Z.; Alexander, M. Atmospheric bridge, oceanic tunnel, and global climatic teleconnections. Rev. Geophys. 2007, 45, RG2005. [CrossRef]

26. Anyamba, A.; Linthicum, K.J.; Small, J.L.; Collins, K.M.; Tucker, C.J.; Pak, E.W.; Britch, S.C.; Eastman, J.R.; Pinzon, J.E.; Russell, K.L. Climate teleconnections and recent patterns of human and animal disease outbreaks. PLoS Negl. Trop. Dis. 2012, 6. [CrossRef] [PubMed]

27. Sanganyado, E.; Lu, Z.; Fu, Q.; Schlenk, D.; Gan, J. Chiral pharmaceuticals: A review on their environmental occurrence and fate processes. Water Res. 2017, 124, 527-542. [CrossRef] [PubMed]

28. Vezzulli, L.; Pruzzo, C.; Huq, A.; Colwell, R.R. Environmental reservoirs of Vibrio cholerae and their role in cholera. Environ. Microbiol. Rep. 2010, 2, 27-33. [CrossRef]

29. Martinelli-Filho, J.E.; Lopes, R.M.; Rivera, I.N.G.; Colwell, R.R. Are natural reservoirs important for cholera surveillance? The case of an outbreak in a Brazilian estuary. Lett. Appl. Microbiol. 2016, 63, 183-188. [CrossRef]

30. Halpern, M.; Broza, Y.B.; Mittler, S.; Arakawa, E.; Broza, M. Chironomid Egg Masses as a Natural Reservoir of Vibrio cholerae Non-O1 and Non-O139 in Freshwater Habitats. Microb. Ecol. 2004, 47, 341-349. [CrossRef]

31. Bwire, G.; Ali, M.; Sack, D.A.; Nakinsige, A.; Naigaga, M.; Debes, A.K.; Ngwa, M.C.; Brooks, W.A.; Garimoi Orach, C. Identifying cholera "hotspots" in Uganda: An analysis of cholera surveillance data from 2011 to 2016. PLoS Negl. Trop. Dis. 2017, 11, e0006118. [CrossRef]

32. Nyenje, P.M.; Foppen, J.W.; Uhlenbrook, S.; Kulabako, R.; Muwanga, A. Eutrophication and nutrient release in urban areas of sub-Saharan Africa-A review. Sci. Total Environ. 2010, 408, 447-455. [CrossRef]

33. Gwenzi, W.; Chaukura, N. Organic contaminants in African aquatic systems: Current knowledge, health risks, and future research directions. Sci. Total Environ. 2018, 619-620, 1493-1514. [CrossRef]

34. Igbinosa, E.O.; Obi, L.C.; Tom, M.; Okoh, A.I. Detection of potential risk of wastewater effluents for transmission of antibiotic resistance from Vibrio species as a reservoir in a peri-urban community in South Africa. Int. J. Environ. Health Res. 2011, 21, 402-414. [CrossRef]

35. Gwenzi, W.; Musiyiwa, K.; Mangori, L. Sources, behaviour and health risks of antimicrobial resistance genes in wastewaters: A hotspot reservoir. J. Environ. Chem. Eng. 2018. [CrossRef]

36. Akoachere, J.F.T.K.; Omam, L.A.; Massalla, T.N. Assessment of the relationship between bacteriological quality of dug-wells, hygiene behaviour and well characteristics in two cholera endemic localities in Douala, Cameroon. BMC Public Health 2013, 13. [CrossRef]

37. Bwire, G.; Mwesawina, M.; Baluku, Y.; Kanyanda, S.S.E.; Orach, C.G. Cross-border cholera outbreaks in Sub-Saharan Africa, the mystery behind the silent illness: What needs to be done? PLoS ONE 2016, 11, 1-15. [CrossRef] [PubMed]

38. Pascual, M.; Bouma, M.J.; Dobson, A.P. Cholera and climate: revisiting the quantitative evidence. Microbes Infect. 2002, 4, 237-245. [CrossRef]

39. Akanda, A.S.; Jutla, A.S.; Islam, S. Dual peak cholera transmission in Bengal Delta: A hydroclimatological explanation. Geophys. Res. Lett. 2009, 36, 1-6. [CrossRef]

40. Schwartz, B.S.; Harris, J.B.; Khan, A.I.; LaRocque, R.C.; Sack, D.A.; Malek, M.A.; Faruque, A.S.G.; Qadri, F.; Calderwood, S.B.; Luby, S.P.; et al. Diarrheal epidemics in Dhaka, Bangladesh, during three consecutive floods: 1988, 1998, and 2004. Am. J. Trop. Med. Hyg. 2006, 74, 1067-1073. [CrossRef] 
41. Lobitz, B.; Beck, L.; Huq, A.; Wood, B.; Fuchs, G.; Faruque, A.S.G.; Colwell, R. Climate and infectious disease: Use of remote sensing for detection of Vibrio cholerae by indirect measurement. Proc. Natl. Acad. Sci. USA 2000, 97, 1438-1443. [CrossRef]

42. Miller, C.J.; Drasar, B.S.; Feachem, R.G. Cholera and Estuarine Salinity in Calcutta and London. Lancet 1982, 319, 1216-1218. [CrossRef]

43. Sirajul Islam, M.; Brooks, A.; Kabir, M.S.; Jahid, I.K.; Shafiqul Islam, M.; Goswami, D.; Nair, G.B.; Larson, C.; Yukiko, W.; Luby, S. Faecal contamination of drinking water sources of Dhaka city during the 2004 flood in Bangladesh and use of disinfectants for water treatment. J. Appl. Microbiol. 2007, 103, 80-87. [CrossRef]

44. Bertuzzo, E.; Mari, L.; Righetto, L.; Gatto, M.; Casagrandi, R.; Rodriguez-Iturbe, I.; Rinaldo, A. Hydroclimatology of dual-peak annual cholera incidence: Insights from a spatially explicit model. Geophys. Res. Lett. 2012, 39, 1-6. [CrossRef]

45. Hashizume, M.; Armstrong, B.; Hajat, S.; Wagatsuma, Y.; Faruque, A.S.G.; Hayashi, T.; Sack, D.A. The effect of rainfall on the incidence of cholera in Bangladesh. Epidemiology 2008, 19, 103-110. [CrossRef] [PubMed]

46. Boraschi, D.; Abebe Alemayehu, M.; Aseffa, A.; Chiodi, F.; Chisi, J.; Del Prete, G.; Doherty, T.M.; Elhassan, I.; Engers, H.; Gyan, B.; et al. Immunity against HIV / AIDS, Malaria, and Tuberculosis during Co-Infections with Neglected Infectious Diseases: Recommendations for the European Union Research Priorities. PLoS Negl. Trop. Dis. 2008, 2, e255. [CrossRef] [PubMed]

47. Weill, F.X.; Domman, D.; Njamkepo, E.; Tarr, C.; Rauzier, J.; Fawal, N.; Keddy, K.H.; Salje, H.; Moore, S.; Mukhopadhyay, A.K.; et al. Genomic history of the seventh pandemic of cholera in Africa. Science 2017, 358, 785-789. [CrossRef] [PubMed]

48. De, R.; Ghosh, J.B.; Sen Gupta, S.; Takeda, Y.; Nair, G.B. The Role of Vibrio cholerae Genotyping in Africa. J. Infect. Dis. 2013, 208. [CrossRef] [PubMed]

49. Waldor, M.K.; RayChaudhuri, D. Treasure trove for cholera research. Nature 2000, 406, 469-470. [CrossRef] [PubMed]

50. Dziejman, M.; Balon, E.; Boyd, D.; Fraser, C.M.; Heidelberg, J.F.; Mekalanos, J.J. Comparative genomic analysis of Vibrio cholerae: Genes that correlate with cholera endemic and pandemic disease. Proc. Natl. Acad. Sci. USA 2002, 99, 1556-1561. [CrossRef]

51. Chun, J.; Grim, C.J.; Hasan, N.A.; Lee, J.H.; Choi, S.Y.; Haley, B.J.; Taviani, E.; Jeon, Y.-S.; Kim, D.W.; Lee, J.-H.; et al. Comparative genomics reveals mechanism for short-term and long-term clonal transitions in pandemic Vibrio cholerae. Proc. Natl. Acad. Sci. USA 2009, 106, 15442-15447. [CrossRef]

52. Kaboré, S.; Cecchi, P.; Mosser, T.; Toubiana, M.; Traoré, O.; Ouattara, A.S.; Traoré, A.S.; Barro, N.; Colwell, R.R.; Monfort, P. Occurrence of Vibrio cholerae in water reservoirs of Burkina Faso. Res. Microbiol. 2017, 169. [CrossRef]

53. Jutla, A.; Aldaach, H.; Billian, H.; Akanda, A.; Huq, A.; Colwell, R. Satellite based assessment of hydroclimatic conditions related to cholera in Zimbabwe. PLoS ONE 2015, 10, 1-17. [CrossRef]

54. Sanganyado, E.; Teta, C.; Masiri, B. Impact of African traditional worldviews on climate change adaptation. Integr. Environ. Assess. Manag. 2018, 14. [CrossRef] [PubMed]

55. Patching, H.M.M.; Hudson, L.M.; Cooke, W.; Garcia, A.J.; Hay, S.I.; Roberts, M.; Moyes, C.L. A Supervised Learning Process to Validate Online Disease Reports for Use in Predictive Models. Big Data 2015, 3, $230-237$. [CrossRef] [PubMed]

56. Midani, F.S.; Weil, A.A.; Chowdhury, F.; Begum, Y.A.; Khan, A.I.; Debela, M.D.; Durand, H.K.; Reese, A.T.; Nimmagadda, S.N.; Silverman, J.D.; et al. Human Gut Microbiota Predicts Susceptibility to Vibrio cholerae Infection. J. Infect. Dis. 2018, 218, 645-653. [CrossRef]

57. Dutilh, B.E.; Thompson, C.C.; Vicente, A.C.P.; Marin, M.A.; Lee, C.; Silva, G.G.Z.; Schmieder, R.; Andrade, B.G.N.; Chimetto, L.; Cuevas, D.; et al. Comparative genomics of 274 Vibrio cholerae genomes reveals mobile functions structuring three niche dimensions. BMC Genomics 2014, 15, 1-11. [CrossRef] [PubMed]

58. Nasr-Azadani, F.; Khan, R.; Rahimikollu, J.; Unnikrishnan, A.; Akanda, A.; Alam, M.; Huq, A.; Jutla, A.; Colwell, R. Hydroclimatic sustainability assessment of changing climate on cholera in the GangesBrahmaputra basin. Adv. Water Resour. 2017, 108, 332-344. [CrossRef]

59. Lee, E.C.; Asher, J.M.; Goldlust, S.; Kraemer, J.D.; Lawson, A.B.; Bansal, S. Mind the scales: Harnessing spatial big data for infectious disease surveillance and inference. J. Infect. Dis. 2016, 214, S409-S413. [CrossRef] [PubMed] 
60. Chunara, R.; Andrews, J.R.; Brownstein, J.S. Social and news media enable estimation of epidemiological patterns early in the 2010 Haitian cholera outbreak. Am. J. Trop. Med. Hyg. 2012, 86, 39-45. [CrossRef]

61. Traore, B.B.; Tangara, F. Data mining techniques on satellite images for discovery of risk areas. Expert Syst. Appl. 2017, 72, 443-456. [CrossRef]

62. Semenza, J.C.; Sudre, B.; Oni, T.; Suk, J.E.; Giesecke, J. Linking Environmental Drivers to Infectious Diseases: The European Environment and Epidemiology Network. PLoS Negl. Trop. Dis. 2013, 7, e2323. [CrossRef]

(C) 2019 by the authors. Licensee MDPI, Basel, Switzerland. This article is an open access article distributed under the terms and conditions of the Creative Commons Attribution (CC BY) license (http:// creativecommons.org/licenses/by/4.0/). 